УДК 53.082.63

DOI: $10.34220 / 2311-8873-2021-4-4-11-15$

К ВОПРОСУ О НАДЕЖНОСТИ СОВРЕМЕННЫХ ЦИФРОВЫХ ЗАПОМИНАЮЩИХ УСТРОЙСТВ Гриднева И.В. ${ }^{1}$, Камалов Н.Р. ${ }^{2}$, Гриднев А.С. ${ }^{1}$

${ }^{1}$ Федеральное государственное бюджетное образовательное учреждение высшего образования «Воронежский государственный аграрный

университет имени императора Петра I»

${ }^{2}$ Федеральное государственное бюджетное образовательное учреждение высшего образования «Воронежский государственный университет»

E-mail: $\underline{\text { rc@icmail.ru }}$

Аннотация: В современной экономике цифровые технологии играют весьма существенную роль. Поэтому надежность работы интегральных схем становится одной из самых актуальных проблем. В статье анализируются результаты оценок надежности запоминающих устройств различной разрядности методом оценки сложности и влияния воздействующих факторов. В результате проведенного исследования выяснилось, что в сочетании с формализованным моделированием данные оценок можно использовать для прогнозирования надежности современных запоминающих устройств любой разрядности.

Ключевые слова: надежность микросхем, сложность цифровых устройств, объем памяти, число отказов, интегральные схемы, внешние факторы.

\title{
TO THE QUESTION OF RELIABILITY OF
} MODERN DIGITAL STORAGE DEVICES Gridneva I.V. ${ }^{1}$, Kamalov N.R. ${ }^{2}$, Gridnev A.S. ${ }^{1}$

${ }^{1}$ Federal State Budget Educational Institution of Higher Education «Voronezh State Agricultural University named after Emperor Peter the Great»

${ }^{2}$ Federal State Budget Educational Institution of Higher Education «Voronezh State University»

E-mail: rc@ @icmail.ru

Summary: Digital technologies play a very significant role In the modern economy. Therefore, the reliability of integrated circuits is one of the most pressing problems. The article analyzes the results of assessing the reliability of storage devices of various capacity by assessing the complexity and influence of external factors. As a result of the study, it was found that, in combination with formalized modeling, the assessment data can be used to predict the reliability of modern storage devices of any capacity. 
Keywords: reliability of microcircuits, complexity of digital devices, memory size, number of failures, integrated circuits, external factors.

Проблема надежности аппаратуры исследуется специалистами на протяжении всего существования электроники. В современном обществе цифровая электроника используется в различных условиях, порой агрессивно влияющих на аппаратуру. Например, контроль за состоянием лесных массивов [1-7] может подвергнуть аппаратуру непредсказуемым нагрузкам. В двадцатом веке активно исследовались проблемы надежности интегральных схем. В результате был разработан метод оценки интенсивности отказов в рамках аддитивной модели, учитывающей такие механизмы отказа, как деградация параметров качества с течением времени и вследствие воздействия окружающей среды [8]. При этом под надежностью понималось свойство изделия сохранять свои характеристики в заданных пределах при определенных условиях эксплуатации. Поэтому концентрировалось внимание на причинах, стимулирующих отказ. Так выяснилось, что деградация с течением времени ускоряется температурой и электрической нагрузкой, воздействием окружающей среды, например, температурным, вызывающим тепловое расширение, влекущее за собой непосредственные и косвенные механические нагрузки.

В рамках такого подхода были разработаны методики оценки, в том числе и для запоминающих устройств (3У), определены ключевые факторы и таблицы их значений. Однако, исследования ограничивались низкоразрядными (до 14 разрядов) устройствами [8].

Цель данной работы - построить физическую модель для расчета надежности запоминающих устройств любой разрядности, базирующуюся на результатах исследований интенсивности отказа ЗУ методом оценки сложности и влияния внешних факторов.

В рамках теории надежности интегральных схем качество устройства моделируется как функция вероятности исправной работы устройства от времени $P(t)$, которая зависит от интенсивности отказов $\lambda[8]$ :

$$
P(t)=e^{-\lambda t}
$$

В свою очередь интенсивность отказов в методе оценки сложности и влияния внешних факторов определяется с использованием зависимостей типа Аррениуса [9] по соотношению [8]: 


$$
\lambda=\Pi_{L} \Pi_{Q}\left(C_{1} \Pi_{T_{1}}+C_{2} \Pi_{E}\right) \Pi_{P},
$$

где $\Pi_{L}-$ коэффициент настроенности технологического процесса, для условий задания; $\Pi_{Q}-$ коэффициент уровня качества, который зависит от сферы эксплуатации изделия; $C_{1}, C_{2}$ - коэффициенты сложности схемы, зависящие от объема памяти $z ; \Pi_{T_{1}}-$ коэффициент ускорения, определяемый температурой перехода, которая рассчитывается для сложных ЗУ как:

$$
T_{j}=T_{\text {окр.сp. }}+25^{0} \mathrm{C},
$$

где $T_{\text {окр.ср }}$ - температура окружающей среды, $\Pi_{E}-$ коэффициент жесткости условий эксплуатации, $\Pi_{p}-$ коэффициент, зависящий от количества выводов ЗУ. Согласно результатам оценок, зависимость интенсивности отказов от объема памяти $3 У$ не является линейной (маркеры на рис. 1).

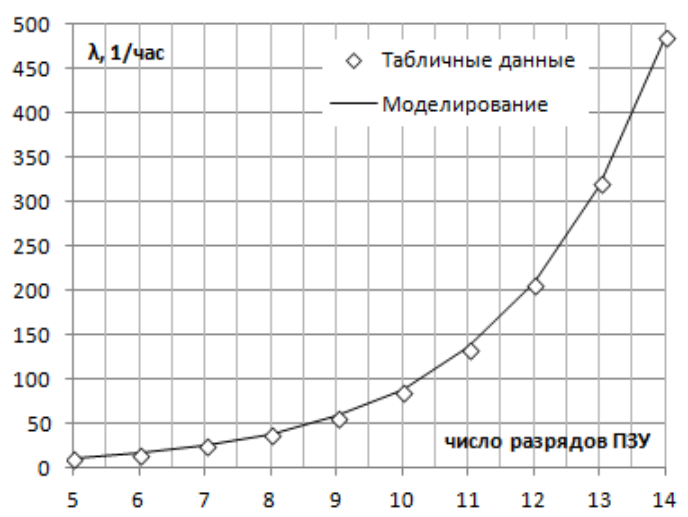

Рисунок 1 - Результаты оценок зависимости интенсивности отказов от числа разрядов ПЗУ (постоянной ЗУ)

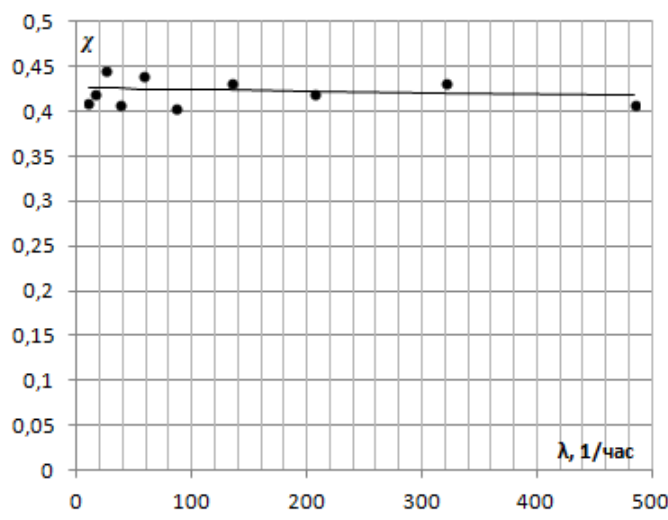

Рисунок 2 - Зависимость величины $\chi$ от $\lambda$

При этом наблюдается увеличение интенсивности отказов с ростом разрядности запоминающего устройства. Поэтому в основании модели было положено предположение, что относительное возрастание интенсивности отказов пропорционально изменению разрядности $3 У$ :

$$
\frac{d \lambda}{\lambda}=\chi d z
$$

где $\chi$ - коэффициент пропорциональности, который тоже убывает с ростом интенсивности отказов, но медленно (рис. 2). Однако, эту зависимость с большой долей вероятности можно считать линейной и моделировать соотношением:

$$
\chi=\chi_{0}-\mu z,
$$


где $\mu$ - коэффициент, обусловленный процессами стабилизации деградации $3 У$. С учетом (5) соотношение (4) преобразуется в дифференциальное уравнение с начальным условием $\lambda=\lambda_{0}$ при $z=z_{0}$. Решение уравнения можно определить аналитически:

$$
\lambda(z)=\frac{\lambda_{0} e^{\chi_{0}\left(z-z_{0}\right)}}{1+\frac{\chi_{0} \lambda_{0}}{\mu}\left(e^{\chi_{0}\left(z-z_{0}\right)}-1\right)} .
$$

Соотношение (6) можно использовать как базовое для формализованной модели с вводными параметрами $\lambda_{0}, \mu, z_{0}$ и $\chi_{0}$. Средствами электронных таблиц была получена зависимость для ПЗУ (на рис. 1 сплошная линия) хорошо согласующаяся с данными расчета (относительная ошибка около $2 \%$ ) при следующих значениях параметров $\left(\lambda_{0}=1,24, \mu / \chi_{0}=0,004 \%\right.$ и $\left.\chi_{0}=0,426\right)$. Программа позволяет с помощью модельного эксперимента определить интенсивность отказов для ЗУ любой разрядности, а с помощью соотношения (1) оценить в рамках стохастической теории надежности вероятность исправной работы устройства. Применение формализованного моделирования один из часто используемых способов при анализе состояния сложных систем [5, 10, 11].

В заключение хотелось бы подчеркнуть, что подобный подход позволяет оценить надежность ЗУ любой разрядности с учетом влияния внешних факторов, причем результаты оценок базируются на данных многолетнего мониторинга качества микросхем. Таким образом, в предложенном методе успешно сочетаются результаты многолетних исследований и принципы современного формализованного моделирования.

\section{СПИСОК ЛИТЕРАТУРЫ}

1 Камалова, Н. С. Цифровые технологии при анализе состояния древесных растений / Н. С. Камалова, Н. Н. Матвеев, С. М. Иванников // Актуальные направления научных исследований XXI века : теория и практика. - 2020. - Т. 8. - № 1 (48). - С. 59-63.

2 Юрьев, Н. Ю. Мониторинг состояния древесных растений с помощью электроизмерительных приборов / Н. Ю. Юрьев, Н. С. Камалова, В. И. Лисицын // Воронежский научно-технический вестник. - 2019. -Т. 2. - № 2 (28). - C. $125-130$.

3 Юрьев, Н. Ю. Схема усиления сигналов датчика температуры в стволах деревьев / Н. Ю. Юрьев, Н. С. Камалова // Современные проблемы естествознания. Инженерный анализ объектов обеспечения авиации : сборник 
материалов 4 Международной научно-практической конференции курсантов и слушателей «Молодежные чтения, посвященные памяти Ю. А. Гагарина», 15 мая 2019 г. / Военный учебно-научный центр Военно-воздушных сил «Военновоздушная академия имени профессора Н. Е. Жуковского и Ю. А. Гагарина». Воронеж : ВУНЦ ВВС «ВВА», 2019. - С. 324-327.

4 Kamalova, N. S. Innovative approach to the assessment of moisture content of forest areas within the framework of the fundamental multi-layered concept / N. S. Kamalova, N. Yu. Evsikova, V. V. Saushkin // IOP Conference Series : Earth and Environmental Science. - 2019. - Vol. 392. - 012043.

5 Евсикова, Н. Ю. Фундаментальная концепция для формализованного моделирования состояния лесных массивов / Н. Ю. Евсикова, Н. С. Камалова, В. В. Саушкин, Н. С. Бокарева // Воронежский научно-технический вестник. 2019. - T. 4. - № 4 (30). - С. 31-36.

6 Камалова, Н. С. Принципиальная схема цифрового датчика контроля состояния древесных растений / Н. С. Камалова, Н. Ю. Евсикова, А. Н. Журавлев // Воронежский научно-технический Вестник. - 2019. - Т. 4. - № 4 (30) - C. 43-47.

7 Евсикова, Н. Ю. Цифровые методы анализа состояния лесных массивов / Н. Ю. Евсикова, Н. С. Камалова, Н. А. Саврасова // Энергоресурсоэффективные экологически безопасные технологии и оборудование : сборник научных трудов международного научно-технического симпозиума «Вторые международные Косыгинские чтения», приуроченные к 100-летию РГУ имени А. Н. Косыгина, 29 октября - 1 ноября 2019 г. / Российский государственный университет имени А. Н. Косыгина. - Москва : РГУ им. А. Н. Косыгина, 2019. - Т. 2. - С. 220-224.

8 Ануфриев, Д. Л. Конструкционные методы повышения надежности интегральных схем : утв. Ред.-издат. сов. БГУИР в качестве учеб. пособия / Д. М. Ануфриев, М. И Горлов, А. П. Достатко. - Минск : Интегралполиграф, 2007. $-264 \mathrm{c}$.

9 Штиллер, В. Уравнение Аррениуса и неравновесная кинетика / В. Штиллер. - Москва : Мир, 2000. - 176 с.

10 Лисицын, В. И. Мониторинг надмолекулярной структуры биокомпозита с помощью формализованного моделирования / В. И. Лисицын, Н. Н. Матвеев, Н. С. Камалова // Физико-математическое моделирование систем : материалы 19 Международного семинара, 24 ноября 2017 г. / Воронежский государственный технический университет. - Воронеж : Воронеж. гос. техн. ун-т, 2018. - С. 141-144.

11 Гриднева, И. В. Исследование транспорта воды в стволах древесных растений методом математического моделирования / И. В. Гриднева, Н. С. Камалова, Н. Ю. Евсикова // Вестник Воронежского государственного аграрного университета. - 2015. - № 1 (44). - С. 58-64. 